\title{
Outcomes of a Resident-Led Early Hospital Discharge Intervention
}

\author{
Nirvani Goolsarran, $\mathrm{MD}^{7}$, Grace Olowo, MD', Yun Ling, Ph.D², Sadia Abbasi, $M D^{7}$, \\ Erin Taub, $\mathrm{MPH}^{7}$, and Getu Teressa, $M D \mathrm{PhD}^{7}$
}

'Department of Medicine, Stony Brook University Hospital, Stony Brook, NY, USA; ${ }^{2}$ Department of Family, Population and Preventive Medicine, Stony Brook University Hospital, Stony Brook, NY, USA.

\begin{abstract}
:
BACKGROUND: Early morning patient discharge from the hospital is increasingly being recognized as a key dimension of quality of care. At our institution, there is a significantly lower early discharge rate on the teaching hospitalist teams in comparison with the non-teaching teams.

OBJECTIVE: To implement a resident-driven intervention in the teaching medical services to increase overall discharge order rate before 11 am (DOB-11) and assess the effect of this intervention on hospital length of stay (LOS), 30-day readmission rates (RR), and resident perception.

DESIGN: Interrupted time series as well as controlled before-after designs.

PARTICIPANTS: All inpatients discharged from general medicine units.

INTERVENTIONS: We implemented an educational didactic in conjunction with resident-attending daily walk rounds followed by resident-led multidisciplinary discharge huddles to identify next-day discharges.

MAIN MEASURES: The primary outcome was DOB-11 rates 18 months pre- and 12 months post-intervention. Secondary outcomes: LOS and RR. Additionally, we assessed residents' perception of the early discharge protocol.
\end{abstract}

KEY RESULTS: The DOB-11 rate increased from 12 to $29 \%(p<0.001)$, LOS increased by 1.47 days $(P<0.001)$, and RR increased by $0.32 \%(P=0.84)$, respectively, on the teaching teams. Compared with the non-teaching (control) teams, the teaching teams registered a greater increase in DOB- 11 rate (by $17 \%, p<0.001$; ratio of adjusted ORs 2.16; 95\% CI, 1.65, 2.85; $p$ value $<0.001$ ), small increase in LOS (by 0.74 day, $p=0.39$; ratio of adjusted post-/pre-intervention ratio [teaching] and post-/ pre- intervention ratio [non-teaching] $=1.05,95 \% \mathrm{CI}$, $0.97,1.14, p=0.23$ ), and relative increase in RR (by $3.98 \%, p=0.07$, and ratio of $\mathrm{ORs}=1.35,95 \% \mathrm{CI}, 1.03$, 1.8), $p=0.03)$. Approximately 55\% (16/29) of the

Prior online publication: This project has not been previously published. Prior abstract/poster presentations: A preliminary analysis of this project was presented as a poster/abstract at the Society of Hospitalist Medicine (SHM) National Meeting, 2018.

Electronic supplementary material The online version of this article (https://doi.org/10.1007/s11606-019-05563-w) contains supplementary material, which is available to authorized users.

Received August 9, 2018

Revised March 29, 2019

Accepted October 22, 2019

Published online December 10, 2019 residents agreed that the early discharge initiative helped in understanding the importance of prioritizing patients for early discharge. Additionally, 55\% (20/36) of the residents "agreed" that the early discharge initiative compromised their learning during teaching rounds.

CONCLUSION: Our study demonstrates that DOB-11 is an achievable goal, not only for non-teaching teams but also for resident-run teaching teams.

KEY WORDS: early hospital discharge; length of stay; readmission.

J Gen Intern Med 35(2):437-43

DOI: $10.1007 /$ s11606-019-05563-w

(c) Society of General Internal Medicine 2019

\section{INTRODUCTION}

Late afternoon hospital discharges are associated with emergency department (ED) overcrowding, ${ }^{1}$ delayed inter-unit patient transfers, lower patient satisfaction, and longer emergency room length of stay. ${ }^{2,3}$ Concerns about safety and quality of care impacted by delayed patient transfer from ED to inpatient beds have led the Joint Commission to implement a "patient flow standard" to prevent crowding and prolonged boarding of patients in the ED and other temporary locations. Early morning discharge of inpatients is suggested as one solution to increase bed availability and timely inter-unit patient transfer. ${ }^{5-7}$ Consequently, early patient discharge from the hospital is progressively being integrated into physicians' performance measures. Despite these efforts, it remains challenging for many institutions to meet these expectations. At our institution, there has been a consistently low rate of early discharges in the teaching teams staffed by residents, interns, and a supervising hospitalist as compared with non-teaching hospitalist teams staffed by an advanced practice provider and a hospitalist. Historically, much of the emphasis is placed at the attendings/hospitalists level in terms of discharge time and rates across institutions. Less emphasis is placed on the analysis of teaching units' workflow and resident participation and leadership in increasing early discharge rates. To our knowledge, there are no studies that focused on specifically promoting residents as frontline champions charged with implementing early discharges. To this end, we implemented and assessed the impact of a resident-driven initiative to increase DOB-11 rates on the teaching teams, and whether this 
will impact LOS, 30-day readmission rates (RR), and resident perception in terms of impact on workflow and learning.

\section{METHODS}

\section{Setting}

The study took place at Stony Brook University Hospital, a tertiary care academic medical center in Long Island, NY. The study was approved by our Institutional Review Board, and no informed consent was required. The general medicine service is comprised of 4 teaching teams with a census of 15 patients, and 10 non-teaching teams with a census of 17 patients each. Each teaching team is staffed with two interns, two medical students, one resident, and a supervising hospitalist. An advanced practice provider and a hospitalist staff each nonteaching team. Both teaching and non-teaching teams consist of a similar population of general medicine patients.

\section{Intervention}

Educational Workshop: Definition of Responsibilities and Instructions for Walk Rounds Checklist Tool. Prior to intervention, a mandatory educational workshop was given to all 96-medicine residents, Post Graduate Year (PGY) one to three. The workshop included education on the importance of early discharge and impact on patient flow. Roles of the resident discharge protocol with a corresponding walk rounds checklist tool and discharge huddle guided template were reviewed (Table 1).

We implemented an early discharge protocol which consists of a two-part resident-led discharge process: Part A: attendingresident walk rounds using a rounding checklist tool and Part B: a multidisciplinary discharge huddle using a guided template.

Table 1 Discharge Walk Rounds Checklist of Tasks

\begin{tabular}{|c|c|c|}
\hline Task & $\begin{array}{l}\text { Responsible team } \\
\text { member }\end{array}$ & $\begin{array}{l}\text { When task } \\
\text { should be } \\
\text { completed }\end{array}$ \\
\hline $\begin{array}{l}\text { Identify and communicate } \\
\text { with the attending-next- } \\
\text { day potential discharges }\end{array}$ & Resident & $\begin{array}{l}\text { During DC } \\
\text { rounds }\end{array}$ \\
\hline Patient education & $\begin{array}{l}\text { Resident with attending } \\
\text { supervision }\end{array}$ & $\begin{array}{l}\text { After DC } \\
\text { rounds }\end{array}$ \\
\hline $\begin{array}{l}\text { Identify transportation/ } \\
\text { home services/PT }\end{array}$ & $\begin{array}{l}\text { Resident will discuss in } \\
\text { multidisciplinary DC } \\
\text { huddle }\end{array}$ & $\begin{array}{l}\text { During DC } \\
\text { rounds }\end{array}$ \\
\hline $\begin{array}{l}\text { Discharge paperwork and } \\
\text { medication reconciliation } \\
\text { for identified next-day } \\
\text { discharges }\end{array}$ & Intern & $\begin{array}{l}\text { After DC } \\
\text { rounds }\end{array}$ \\
\hline Discharge order in EMR & Resident & $\begin{array}{l}\text { Early am of } \\
\text { DC }\end{array}$ \\
\hline $\begin{array}{l}\text { Patient assessment for } \\
\text { change }\end{array}$ & Resident and attending & $\begin{array}{l}\text { Early am of } \\
\text { DC }\end{array}$ \\
\hline $\begin{array}{l}\text { Final lab tests/review (this } \\
\text { should be ordered for } \\
\text { 4am) }\end{array}$ & Resident and attending & $\begin{array}{l}\text { Early am of } \\
\text { DC }\end{array}$ \\
\hline
\end{tabular}

PT physical therapy, DC discharge, EMR electronic medical record
Attending-Resident Walk Rounds. Attending and the senior resident for the team are required to conduct 20-30-min brief walk rounds between the hours of 2-4 pm to identify next-day discharges. During the walk rounds, senior resident and attending select patients that are appropriate for next-day discharges and conduct the following: (1) Discussion with the patient and family members about the plan for early morning of the following day, (2) Identifying if there are pending needs such as transportation, home care set up, physical therapy, etc. The checklist is to be completed by the resident after discussion with the supervising hospitalist during walks rounds (Table 1).

Multidisciplinary Discharge Huddle. After walk rounds, the senior resident attends $4 \mathrm{pm}$ multidisciplinary discharge huddle with the case managers, social workers, and physical therapist to inform the team of the next-day potential discharges based on the completed checklist and discussion with the attending hospitalist. In order to guide the resident discussion during multidisciplinary rounds, a guided template was created to keep the discussion succinct with a focus on barriers to the next-day discharges identified (Online Appendix A). By the end of the day, the senior resident is responsible for supervising the interns and ensuring that the discharge paperwork and medication reconciliation are pre-planned and ready for next-day early discharge.

On the day of discharge, the patients identified from the previous day are prioritized for discussion on morning rounds at $9 \mathrm{am}$. After verbal discussion and patient evaluation with the supervising hospitalist, the senior resident places the early discharge order before 11 am.

Resident Buy-in/Ongoing Reminders and Weekly Feedback. The discharge educational workshops given prior to the intervention focused on emphasis on the positive impact of early discharge on workflow. A PGY 3 resident volunteered to be the designated early discharge resident champion. The resident champion sent daily pager or in-person reminders for walk rounds and discharge huddle. Additionally, the residency program directors emphasized the importance of early discharges during weekly resident reports.

Engaging the Hospitalists. Ongoing meetings took place with all teaching hospitalists with leadership (Chair of medicine and Division director) to educate faculty members on the early discharge protocol.

\section{Data Collection and Analysis}

Primary Outcome: Calendar Months Discharge Order Before-11 Percentages (DOB-11). To match our organizational criteria for early discharge, we recorded the date and time of the discharge order in the electronic medical record (EMR). We excluded patients categorized as "observation" status and deaths, and patients who left against medical advice. We analyzed 13, 781 patient visits during the pre-intervention 
(January 1, 2016 to June 30, 2017) and post-intervention (August 1, 2017, through July 31, 2018) periods and excluded the transitional month of July 2017.

Secondary Outcomes: LOS and 30-Day RR. For secondary outcomes, we compared the LOS and 30-day RR during the periods before and after the intervention, and between teaching and control non-teaching teams.

Resident Trainee Perception. We assessed resident perception on the impact of the early discharge protocol in terms of their learning and change in daily workflow. A 4-question Likert scale electronic survey was sent to 58 residents who participated in the early discharge protocol 6 months after the intervention. Surveys were anonymous and voluntary and consisted of a free text field to allow residents the opportunity to identify any perceived barriers faced with the early discharge initiative (Online Appendix B).

Statistical Analysis. The Interrupted Time Series (ITS) regression analysis was performed to assess the secular trends in the outcomes during pre- and post-intervention periods. Although the intervention was introduced in the teaching teams only, we included a comparable control series (non-teaching teams) in a comparative design using multi-interrupted time series analysis (MITSA) to strengthen the result and interpretation of the single ITS analysis (SITSA).

The interrupted time series analysis cannot adjust for covariates; therefore, we additionally performed a controlled before-after intervention analysis by adjusting covariates in a multivariable mixed effect regression analysis.

"Univariate" mixed effect models were initially utilized to examine the marginal association between variables and the outcomes. Beside baseline variables, the "univariate" mixed effect model also included teaching vs. non-teaching and preand post-intervention and the interaction between teaching team status and pre-/post-intervention. For DOB-11 and 30day RR, logistic mixed effect models were used. LOS was logtransformed to have better normality, and a linear mixed effect model was used. Factors that were significantly associated ( $p$ value $<0.05$ ) with the outcome based on univariate mixed effect model were included in the final multivariable mixed effect model. The interaction terms between pre-/post-intervention and teaching/non-teaching were included in the final models regardless of its significance.

All statistical analyses were performed using SAS 9.4 (SAS Institute Inc., Cary, NC). Significance level was set at 0.05 .

\section{RESULTS}

\section{Demographics and Baseline Characteristics}

Table 2 shows patient demographics and baseline characteristics according to the pre- and post-intervention as well as teaching and non-teaching team status. The baseline characteristics of the study population were identical between teaching and non-teachings teams except for minor differences in the racial/ethnic compositions. The patient population during the post- vs. pre-intervention period had higher mean Charlson comorbidity score in both the teaching (2.9 vs. 2.5, $p<0.001)$ and the non-teaching teams $(2.8$ vs. $2.6, p=0.002)$.

\section{Primary Outcome: Rate of DOB-11}

The DOB-11 rate increased from a pre-intervention baseline rate of 12 to $29 \%(p<0.001)$. The ITS analysis (Fig. 1) showed that there was a significant boost in the DOB-11 rate in both teaching (increased by $25 \%, p<0.001$ ) and nonteaching teams (increased by $8 \%, p=0.001$ ) after the intervention was introduced to the teaching teams. The increase in DOB-11 is calculated by the predicted early discharge rate at month 20 (the month after intervention) and month 18 (the month before intervention). However, the post-intervention period increase in DOB-11 rate was significantly larger in the teaching teams compared with the non-teaching teams (difference of $17 \%, p<0.001$ ). Additionally, the controlled before-after analysis of the DOB-11 (Table 3) further confirmed the results of the ITS analysis. In a multivariable logistic model, both teaching and non-teaching teams registered increased rates of DOB-11 (teaching teams $\mathrm{OR}=3.16$, $95 \% \mathrm{CI}, 2.48,4.03, p<0.001$; non-teaching teams $\mathrm{OR}=1.46$, $95 \% \mathrm{CI}, 1.29,1.66, p<0.001)$ but the increase in DOB-11 in the teaching teams was more than double that of the nonteaching teams (ratio of ORs $=2.16,95 \% \mathrm{CI}, 1.65,2.85$, $p<0.001)$.

\section{Secondary Outcomes: LOS and 30-Day RR}

The observed LOS during the post-intervention period increased by 1.47 days $(p<0.001)$ in the teaching teams and by 0.73 day $(p=0.38)$ in the non-teaching teams (Fig. 2). However, the difference in the increase for teaching vs. nonteaching teams was not statistically significant (teaching teams registered 0.74 day more increase in LOS than the nonteaching teams, $p=0.39$ ).

Most of the findings from ITS analysis were replicated in the controlled before-after analysis (Table 3). In a multivariable linear regression model, there was an increase in LOS in the teaching teams $(1.12,95 \% \mathrm{CI}, 1.05,1.20, p=0.004)$ but the non-teaching teams also showed an increase $(1.07,95 \%$ CI, 1.03, 1.12, $p=0.01)$. However, consistent with the ITS analysis, there was no statistically significant difference in the relative increase in LOS between teaching and non-teaching teams (ratio $=1.05,95 \% \mathrm{CI}, 0.97,1.14, p=0.23$ ).

We found no statistically significant difference in the average 30-day RR between post-intervention vs. pre-intervention periods in the teaching teams (increased by $0.32 \%, p=0.84$, and $\mathrm{OR}=1.08,95 \% \mathrm{CI}, 0.87,1.35 p=0.49$ ) but the nonteaching teams registered a statistically significant reduction in 30-day RR during the post-intervention period (decreased by $3.67 \%, p=0.02$, and $\mathrm{OR}=0.80,95 \% \mathrm{CI}, 0.68,0.95, p=$ 
Table 2 Patient Demographics and Baseline Characteristics According to Pre- and Post-intervention as well as Teaching and Non-teaching Group Status

\begin{tabular}{|c|c|c|c|c|c|c|c|c|c|c|}
\hline \multirow{2}{*}{\multicolumn{2}{|c|}{ Variable }} & \multirow[t]{2}{*}{ All } & \multicolumn{2}{|c|}{$\begin{array}{l}\text { Non-teaching }(n= \\
\text { 8730) }\end{array}$} & \multicolumn{2}{|c|}{$\begin{array}{l}\text { Teaching }(n= \\
\text { 5051) }\end{array}$} & \multicolumn{4}{|l|}{$p$ value } \\
\hline & & & $\begin{array}{l}\text { Pre }(n= \\
\text { 6061) }\end{array}$ & $\begin{array}{l}\text { Post } \\
(n= \\
2669)\end{array}$ & $\begin{array}{l}\text { Pre } \\
(n= \\
2430)\end{array}$ & $\begin{array}{l}\text { Post } \\
(n= \\
2621)\end{array}$ & $\begin{array}{l}\text { Non- } \\
\text { teaching, } \\
\text { pre vs. post }\end{array}$ & $\begin{array}{l}\text { Teaching, } \\
\text { pre vs. post }\end{array}$ & $\begin{array}{l}\text { Pre, non- } \\
\text { teach vs. } \\
\text { teach }\end{array}$ & $\begin{array}{l}\text { Post, } \\
\text { non- } \\
\text { teach vs. } \\
\text { teach }\end{array}$ \\
\hline \multirow{2}{*}{\multicolumn{2}{|c|}{$\begin{array}{l}\text { Age }(\text { mean } \pm \mathrm{SD}) \\
\text { Female, } n(\%)\end{array}$}} & $67 \pm 19$ & $67 \pm 19$ & $67 \pm 19$ & $67 \pm 19$ & $66 \pm 19$ & 0.23 & 0.20 & 0.52 & 0.08 \\
\hline & & $\begin{array}{l}6988 \\
(50.7)\end{array}$ & $3061(50.5)$ & $\begin{array}{l}1376 \\
(51.6)\end{array}$ & $\begin{array}{l}1214 \\
(50.0)\end{array}$ & $\begin{array}{l}1337 \\
(51.0)\end{array}$ & 0.37 & 0.47 & 0.65 & 0.69 \\
\hline \multirow[t]{5}{*}{ Race, $n(\%)$} & Asian & $\begin{array}{l}261 \\
(1.9)\end{array}$ & 112 (1.9) & $\begin{array}{l}47 \\
(1.8)\end{array}$ & $\begin{array}{l}36 \\
(1.5)\end{array}$ & $\begin{array}{l}66 \\
(2.5)\end{array}$ & 0.002 & 0.06 & 0.01 & 0.02 \\
\hline & Black & $\begin{array}{l}927 \\
(6.7)\end{array}$ & $436(7.2)$ & $\begin{array}{l}165 \\
(6.2)\end{array}$ & $\begin{array}{l}151 \\
(6.2)\end{array}$ & $\begin{array}{l}175 \\
(6.7)\end{array}$ & & & & \\
\hline & Hispanic & $\begin{array}{l}388 \\
(2.8)\end{array}$ & $177(2.9)$ & $\begin{array}{l}69 \\
(2.6)\end{array}$ & $\begin{array}{l}68 \\
(2.8)\end{array}$ & $\begin{array}{l}74 \\
(2.8)\end{array}$ & & & & \\
\hline & Other & $\begin{array}{l}1278 \\
(9.3)\end{array}$ & $598(9.9)$ & $\begin{array}{l}222 \\
(8.3)\end{array}$ & $\begin{array}{l}215 \\
(8.9)\end{array}$ & $\begin{array}{l}243 \\
(9.3)\end{array}$ & & & & \\
\hline & White & $\begin{array}{l}10,927 \\
(79.3)\end{array}$ & $4738(78.2)$ & $\begin{array}{l}2166 \\
(81.2)\end{array}$ & $\begin{array}{l}1960 \\
(80.7)\end{array}$ & $\begin{array}{l}2063 \\
(78.7)\end{array}$ & & & & \\
\hline \multicolumn{2}{|c|}{$\mathrm{BMI}($ mean $\pm \mathrm{SD})$} & $\begin{array}{l}28.3 \pm \\
7.7\end{array}$ & $28.4 \pm 7.8$ & $\begin{array}{l}28.3 \pm \\
7.8\end{array}$ & $\begin{array}{l}28.4 \pm \\
7.5\end{array}$ & $\begin{array}{l}28.2 \pm \\
7.6\end{array}$ & 0.78 & 0.39 & 0.87 & 0.64 \\
\hline \multicolumn{2}{|c|}{$\begin{array}{l}\text { Comorbidity score (mean } \pm \\
\text { SD) }\end{array}$} & $2.7 \pm 2.6$ & $2.6 \pm 2.6$ & $\begin{array}{l}2.8 \pm \\
2.7\end{array}$ & $\begin{array}{l}2.5 \pm \\
2.5\end{array}$ & $\begin{array}{l}2.9 \pm \\
2.7\end{array}$ & 0.002 & $<0.001$ & 0.07 & 0.43 \\
\hline \multirow{5}{*}{$\begin{array}{l}\text { Discharge } \\
\text { Location, } n \\
(\%)\end{array}$} & AMA & $\begin{array}{l}215 \\
(1.6)\end{array}$ & $98(1.6)$ & $\begin{array}{l}48 \\
(1.8)\end{array}$ & $\begin{array}{l}28 \\
(1.2)\end{array}$ & $\begin{array}{l}41 \\
(1.6)\end{array}$ & 0.002 & 0.03 & 0.18 & 0.12 \\
\hline & Home & $\begin{array}{l}9980 \\
(72.4)\end{array}$ & $4429(73.1)$ & $\begin{array}{l}1861 \\
(69.7)\end{array}$ & $\begin{array}{l}1809 \\
(74.4)\end{array}$ & $\begin{array}{l}1881 \\
(71.8)\end{array}$ & & & & \\
\hline & Other & $\begin{array}{l}246 \\
(1.8)\end{array}$ & $105(1.7)$ & $\begin{array}{l}62 \\
(2.3)\end{array}$ & $\begin{array}{l}37 \\
(1.5)\end{array}$ & $\begin{array}{l}42 \\
(1.6)\end{array}$ & & & & \\
\hline & $\begin{array}{l}\text { Skilled } \\
\text { facility }\end{array}$ & $\begin{array}{l}3086 \\
(22.4)\end{array}$ & $1315(21.7)$ & $\begin{array}{l}645 \\
(24.2)\end{array}$ & $\begin{array}{l}512 \\
(21.1)\end{array}$ & $\begin{array}{l}614 \\
(23.4)\end{array}$ & & & & \\
\hline & Transfer & $\begin{array}{l}254 \\
(1.8)\end{array}$ & 114 (1.9) & $53(2)$ & $\begin{array}{l}44 \\
(1.8)\end{array}$ & $\begin{array}{l}43 \\
(1.6)\end{array}$ & & & & \\
\hline \multirow[t]{4}{*}{$\begin{array}{l}\text { Admission } \\
\text { source, } n(\%)\end{array}$} & ED & $\begin{array}{l}11,496 \\
(83.4)\end{array}$ & $5222(86.2)$ & $\begin{array}{l}2123 \\
(79.5)\end{array}$ & $\begin{array}{l}2101 \\
(86.5)\end{array}$ & $\begin{array}{l}2050 \\
(78.2)\end{array}$ & $<0.001$ & $<0.001$ & 0.58 & 0.41 \\
\hline & Other & $45(0.3)$ & $16(0.3)$ & $\begin{array}{l}16 \\
(0.6)\end{array}$ & $3(0.1)$ & $\begin{array}{l}10 \\
(0.4)\end{array}$ & & & & \\
\hline & Referral & $\begin{array}{l}835 \\
(6.1)\end{array}$ & $265(4.4)$ & $\begin{array}{l}182 \\
(6.8)\end{array}$ & $\begin{array}{l}137 \\
(5.6)\end{array}$ & $\begin{array}{l}251 \\
(9.6)\end{array}$ & & & & \\
\hline & Transfer & $\begin{array}{l}1405 \\
(10.2)\end{array}$ & $558(9.2)$ & $\begin{array}{l}348 \\
(13.0)\end{array}$ & $\begin{array}{l}189 \\
(7.8)\end{array}$ & $\begin{array}{l}310 \\
(11.8)\end{array}$ & & & & \\
\hline \multicolumn{2}{|l|}{ DOB-11, $n(\%)$} & $\begin{array}{l}4840 \\
(35)\end{array}$ & $2429(40)$ & $\begin{array}{l}1367 \\
(51)\end{array}$ & $\begin{array}{l}294 \\
(12)\end{array}$ & $\begin{array}{l}750 \\
(29)\end{array}$ & $<0.001$ & $<0.001$ & $<0.001$ & $<0.001$ \\
\hline \multirow{2}{*}{\multicolumn{2}{|c|}{$\begin{array}{l}\text { Length of stay, days (mean } \\
\pm \mathrm{SD}) \\
\text { 30-day Readmission, } n(\%)\end{array}$}} & $\begin{array}{l}7.1 \pm \\
18.9\end{array}$ & $7.36 \pm 19.1$ & $\begin{array}{l}8.5 \pm \\
30.7\end{array}$ & $\begin{array}{l}5.65 \pm \\
6.4\end{array}$ & $\begin{array}{l}6.52 \pm \\
7.3\end{array}$ & 0.07 & $<0.001$ & $<0.001$ & 0.001 \\
\hline & & $\begin{array}{l}1573 \\
(11.4)\end{array}$ & 702 (11.6) & $\begin{array}{l}258 \\
(9.7)\end{array}$ & $\begin{array}{l}283 \\
(11.7)\end{array}$ & $\begin{array}{l}330 \\
(12.6)\end{array}$ & 0.01 & 0.31 & 0.94 & $<0.001$ \\
\hline
\end{tabular}

$p$ values are based on linear mixed effect model (age, BMI, comorbidity score, and length of stay), logistic mixed effect model (gender and teaching group), or ordinal mixed effect model (race, discharge location, and financial class). Since some patients have multiple visits, mixed effect models were used to take into account within-subject correlation

0.01) (Fig. 3: ITS analysis and Table 3: controlled before-after analysis). As a result of the aforementioned opposite trends, there was a relative increase in 30-day RR in the teaching teams compared with non-teaching teams (the difference was $3.98 \%, p=0.07$, and ratio of ORs $=1.35,95 \% \mathrm{CI}, 1.03,1.78)$ $(p=0.03)$.

\section{Secondary Outcome: Trainees Perception of Early Discharge Intervention}

29 out of $58(50 \%)$ internal medicine residents participated and completed the post-intervention survey. Sixteen (16) out of $29(55 \%)$ of the residents "strongly agreed" or "agreed" that the early discharge initiative helped in understanding the importance of prioritizing patients for early discharge. Conversely, the same percentage of the residents "strongly agreed" or "agreed" that the early discharge initiative compromised their learning during teaching rounds. The most commonly cited reasons for compromised learning were as follows: (1) prioritization of early discharge took away valuable time from teaching during more active teaching cases, (2) inappropriate focus on stable patients that are ready for discharge. Overall, 12 out of $26(41 \%)$ of the residents reported that prioritizing early discharge is likely to have a positive impact on future clinical practice.

\section{DISCUSSION AND LIMITATIONS}

In this relatively large observational study, we used complementary study designs and analytical approaches to demonstrate that increasing early morning patient discharge can be 


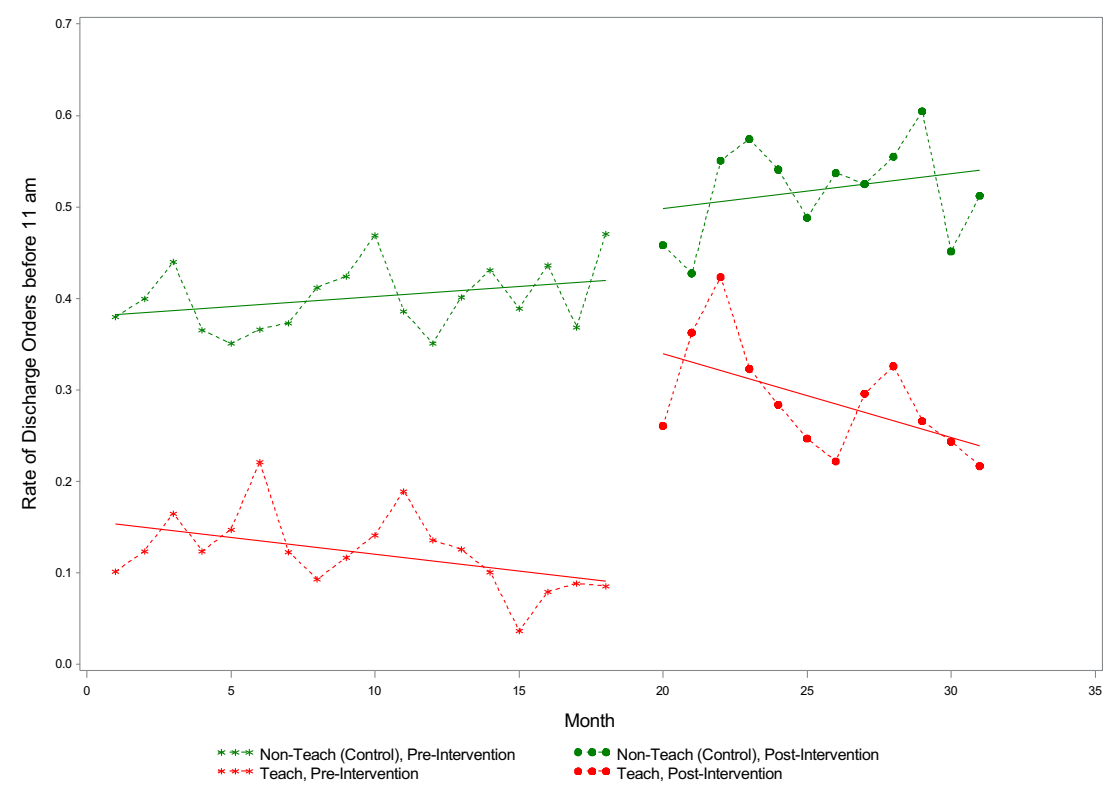

Fig. 1 Interrupted time series analysis results for the rate of discharge orders before 11 am (DOB-11), before and after the intervention, by teaching groups and non-teaching groups (control).

Table 3 Controlled Before-After Intervention Multivariable Mixed Effect Analysis of the Primary and Secondary Outcomes: Postintervention vs. Pre-intervention Period Changes in Outcomes Were Assessed for the Teaching Teams and Compared with Changes in the Non-teaching Teams

\begin{tabular}{|c|c|c|c|}
\hline Variable & Levels & $\begin{array}{l}\text { Value }^{1} \\
(95 \% \mathrm{CI})\end{array}$ & $p$ value \\
\hline \multirow[t]{3}{*}{$\begin{array}{l}\text { Early discharge } \\
\text { before } 11 \mathrm{am}^{2}\end{array}$} & $\begin{array}{l}\text { Post-intervention vs. } \\
\text { pre-intervention } \\
\text { (teaching) }\end{array}$ & $\begin{array}{l}3.16 \\
(2.48 \\
4.03)\end{array}$ & $<0.0001$ \\
\hline & $\begin{array}{l}\text { Post-intervention vs. } \\
\text { pre-intervention (non- } \\
\text { teaching) }\end{array}$ & $\begin{array}{l}1.46 \\
(1.29 \\
1.66)\end{array}$ & $<0.0001$ \\
\hline & \multicolumn{3}{|c|}{$\begin{array}{l}\text { OR of Post-intervention vs. pre-intervention } \\
\text { (teaching) vs. OR of post-intervention vs. pre- } \\
\text { intervention (non-teaching) }\end{array}$} \\
\hline \multirow[t]{4}{*}{$\begin{array}{l}\text { LOS (length of } \\
\text { stay) }\end{array}$} & $\begin{array}{l}\text { Post-intervention vs. } \\
\text { pre-intervention } \\
\text { (teaching) }\end{array}$ & $\begin{array}{l}1.12 \\
(1.05 \\
1.20)\end{array}$ & 0.004 \\
\hline & $\begin{array}{l}\text { Post-intervention vs. } \\
\text { pre-intervention (non- } \\
\text { teaching) }\end{array}$ & $\begin{array}{l}1.07 \\
(1.03 \\
1.12)\end{array}$ & 0.01 \\
\hline & \multirow{2}{*}{\multicolumn{3}{|c|}{$\begin{array}{l}\text { Ratio of post-intervention vs. pre-intervention } \\
\text { (teaching) vs. ratio of post-intervention vs. pre- } \\
\text { intervention (non-teaching) } \\
\text { Ratio of ratios }=1.05(0.97,1.14), p \text { value } 0.23\end{array}$}} \\
\hline & & & \\
\hline \multirow[t]{3}{*}{ Readmission $^{2}$} & $\begin{array}{l}\text { Post-intervention vs. } \\
\text { pre-intervention } \\
\text { (teaching) }\end{array}$ & $\begin{array}{l}1.08 \\
(0.87 \\
1.35)\end{array}$ & 0.49 \\
\hline & $\begin{array}{l}\text { Post-intervention vs. } \\
\text { pre-intervention (non- } \\
\text { teaching) }\end{array}$ & $\begin{array}{l}0.80 \\
(0.68 \\
0.95)\end{array}$ & 0.01 \\
\hline & \multicolumn{3}{|c|}{$\begin{array}{l}\text { OR of post-intervention vs. pre-intervention } \\
\text { (teaching) vs. OR of post-intervention vs. pre- } \\
\text { intervention (non-teaching) } \\
\text { Ratio of ORs }=1.35(1.03,1.78), p \text { value } 0.03\end{array}$} \\
\hline
\end{tabular}

${ }^{1}$ Values are odds ratio (early discharge and readmission) or ratio (LOS) ${ }^{2}$ Logistic mixed effect models adjusted for age, admission source, comorbidity score (early discharge before 11 am) or adjusted for discharge location, admission source, and comorbidity score (readmission)

${ }^{3}$ Linear mixed effect model for log-transformed LOS (length of stay). Adjusted for age, gender, race, discharge location, financial class, admission source, and comorbidity score achieved by implementation of a multidisciplinary discharge process. Although the DOB-11 rate in our study was increased in both the intervention (teaching teams) and the comparison non-teaching teams, the increase in DOB-11 rate was significantly larger in the teaching teams compared with the nonteaching teams, strongly indicating an effect attributable to the intervention independent of secular trends and baseline characteristics. We noted an initial rapid rise in DOB-11 trend immediately after the intervention, followed by a gradual decline over time. A decrease in adherence to the protocol is a potential explanation for the observed trends in DOB- 11 . This highlights the importance of sustainability planning (e.g., direct oversight of compliance and feedback) to maintain outcome achievements following quality improvement initiatives. Although similar effective interdisciplinary initiatives were shown to increase early morning discharges, ${ }^{8}$ our intervention was unique in that it placed residents in our teaching medical services as champions of the initiative.

One of the common concerns raised with early morning discharge initiative is its impact on other hospital outcomes such as LOS and 30-day RR. Our finding showed no significant change in the 30-day RR during the post-intervention period in the teaching teams. Consistent with a previous report, ${ }^{8}$ this finding suggests a neutral impact of the initiative on the 30-day RR. However, this assertion is not supported by the result showing a significant reduction in the 30-day RR in the non-teaching (control) team during the post-intervention period. There was no initiative that could account for the reduction in the 30-day RR in the non-teaching teams. Therefore, this outcome must be closely monitored in future studies. We found an increased LOS during the post-intervention period in the teaching teams. However, the non-teaching teams which were not subjected to the intervention also showed an increase in LOS that was comparable with the increase in LOS 


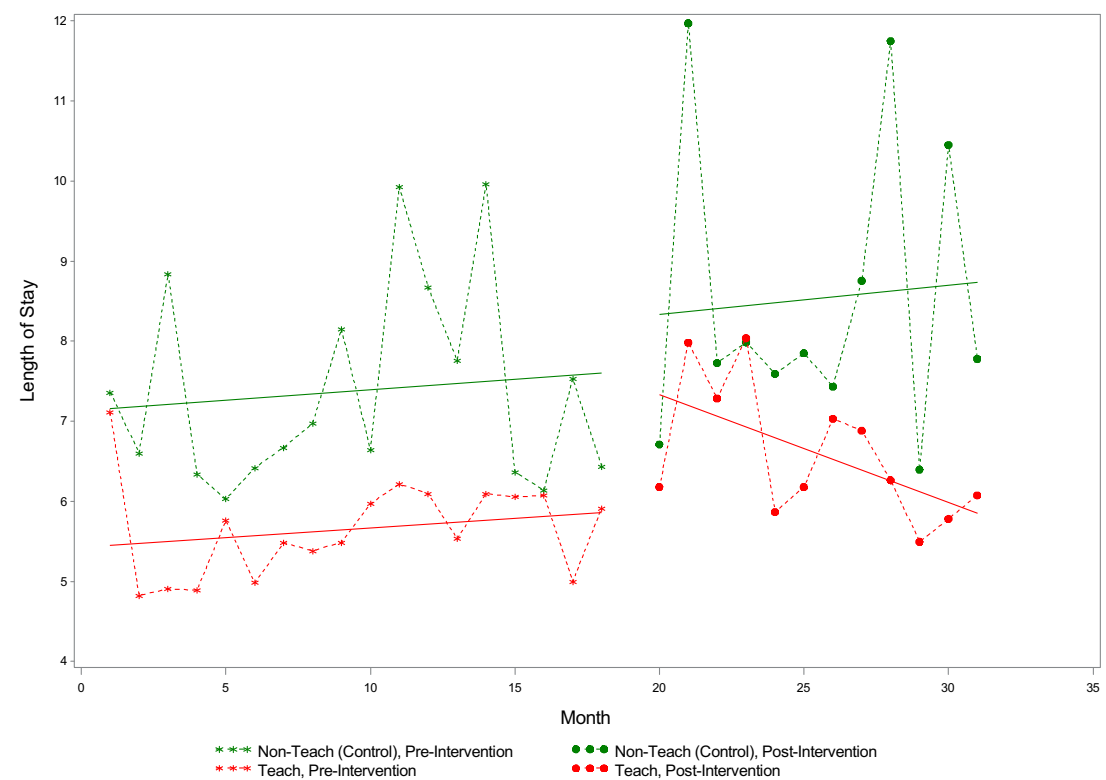

Fig. 2 Interrupt time series analysis results for length of stay (LOS), before and after implementation of intervention, by teaching group and non-teaching group (control).

registered in the teaching teams, suggesting that the intervention per se might not be responsible for this trend. Although the post-intervention period patient population had higher comorbidity index, our multivariable adjusted analysis also demonstrated longer LOS in the post-intervention period. It is unclear what unmeasured confounder could have accounted for this trend. Two prior studies that evaluated the impact of a successful early patient discharge initiative on LOS had contrasting results. Wertheimer et al. ${ }^{8}$ found a small decrease in observed over expected LOS following its intervention. Contrasting the report by Wertheimer et al., ${ }^{8}$ a retrospective study of 38,365 medical and surgical patients by Rajkomar et al. ${ }^{9}$ showed an association between longer LOS and early morning hospital discharge (adjusted odds ratio 1.04, 95\% CI 1.001.09). Taken together, these studies evaluating the impact of early discharge interventions on LOS show contrasting results, which are likely due to differences in institutional settings, interventions, patient populations, research methodology, and research analysis as well as the presences of other unmeasured co-interventions. ${ }^{10}$

Our intervention was carried out in teaching hospitalist services and required revision of the resident workflow in order to integrate early discharge as part of the routine daily flow. Resident trainees are frontline providers and are well

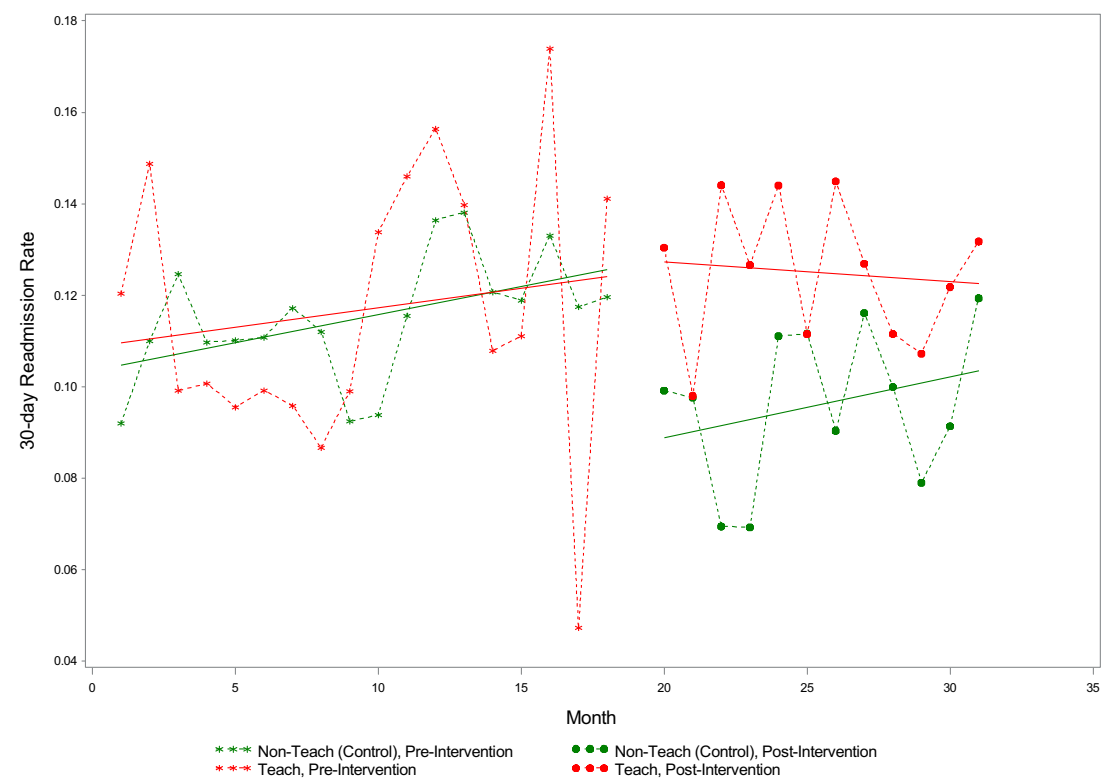

Fig. 3 Interrupt time series analysis results for 30-day readmission rate, before and after implementation of intervention, by teaching group and non-teaching group (control). 
suited to identify and conduct early morning discharges of hospitalized patients. Teaching hospitals are charged with ensuring that trainees acquire meaningful and measurable skills in order to meet the increasing demand for efficiency upon graduation. To our knowledge, this is the first report on early morning discharge initiative engaging trainees as champions and assessing the impact of early morning discharge initiative on the learning environment or perception of trainees.

We believe that the early discharge initiatives are highly replicable at other institutions.

We believe the success of our program was reliant on 4 important factors: (1) identification of resident champions to promote peer leadership, (2) revision of the resident workflow to accommodate afternoon walking rounds and discharge huddles, (3) utilization of tools to standardize communication for prioritization of early discharges, (4) engagement of the leaders of the residency program to ensure the alignment of the hospital initiative with residency training. By incorporating all four factors, we were able to ensure buy-in and compliance with the intervention from all participating members. The social workers and case managers were key players in implementing the discharge huddle. They had a strong desire to participate since obtaining communication about discharge planning on the day prior was very helpful for their preparation of patient discharges.

There are several limitations of this study, beyond the inherent limitations of a pre-and post-retrospective observation design. First, it was a single center study at a large academic residency program, thus limiting its generalizability. We also acknowledge the limitation of the non-teaching teams as control group since there are substantial differences with the teaching teams with respect to the composition of team members and patient census. The hospital-wide heightened awareness of the importance of DOB-11 and increased emphasis on DOB-11 as a key performance measure for hospitalists may have elicited the Hawthorne effect, and this may be responsible for measurable changes in outcomes in the control nonteaching teams. We did not consider other important outcomes such as patient satisfaction and adverse events. Our focus for this study was to assess the impact on the intervention on early discharge rates and corresponding LOS, RR, and resident perception.

Although the early discharge initiative had perceived positive impact on clinical practice, a sizable fraction of surveyed trainees perceived the intervention had a negative impact on their learning. However, the sample size for the resident survey was small and the response rate was low which limits our ability to make a strong conclusion. Therefore, it is difficult to ascertain as to whether the early discharge initiative truly impacted education. Future studies can measure change in residents' In-Training Exam Scores or overall medical knowledge milestones to assess changes in learning outcomes. We also did not conduct surveys to assess perceptions of the attending physicians. Therefore, we cannot make a comparison of the attending's perception with the trainee's perception.

Another limitation of the study is the lack of direct observation of compliance rate as part of the initiative's sustainability planning. Finally, we believe future research should look at more long-term impacts of early morning discharge interventions on ED crowding, boarding time, patient safety, cost, and both trainees' and attending physicians' perception.

Acknowledgments: We acknowledge Biostatistical Consulting Core, School of Medicine, Stony Brook University, for biostatistical support.

Corresponding Author: Getu Teressa, MD PhD; Department of Medicine, Stony Brook University Hospital, Stony Brook, NY, USA (e-mail: getu.teressa@stonybrookmedicine.edu).

Funding Information This study was funded by a contribution from Stony Brook University School of Medicine Office of the Dean of Research.

\section{Compliance with Ethical Standards:}

The study was approved by our Institutional Review Board, and no informed consent was required.

Conflict of Interest: The authors declare that they have no competing or conflict of interest.

\section{REFERENCES}

1. Khanna, S., et al., Impact of admission and discharge peak times on hospital overcrowding. Stud Health Technol Inform, 2011. 168: p. 82-8.

2. Derlet, R.W. and J.R. Richards, Overcrowding in the nation's emergency departments: complex causes and disturbing effects. Ann Emerg Med, 2000. 35(1): p. 63-8.

3. White, B.A., et al., Boarding inpatients in the emergency department increases discharged patient length of stay. J Emerg Med, 2013. 44(1): p. 230-5.

4. Than, M., et al., What is an acceptable risk of major adverse cardiac event in chest pain patients soon after discharge from the Emergency Department?: a clinical survey. Int J Cardiol, 2013. 166(3): p. 752-4.

5. Powell, E.S., et al., The relationship between inpatient discharge timing and emergency department boarding. J Emerg Med, 2012. 42(2): p. 18696.

6. Wertheimer, B., et al., Discharge before noon: Effect on throughput and sustainability. J Hosp Med, 2015. 10(10): p. 664-9.

7. Kravet, S.J., et al., Discharging patients earlier in the day: a concept worth evaluating. Health Care Manag (Frederick), 2007. 26(2): p. 142-6.

8. Wertheimer, B., et al., Discharge before noon: an achievable hospital goal. J Hosp Med, 2014. 9(4): p. 210-4.

9. Rajkomar, A., et al., The association between discharge before noon and length of stay in medical and surgical patients. J Hosp Med, 2016. 11(12): p. 859-861.

10. Shine, D., Discharge before noon: an urban legend. Am J Med, 2015. 128(5): p. 445-6.

Publisher's Note Springer Nature remains neutral with regard to jurisdictional claims in published maps and institutional affiliations. 